\title{
Dietary Practices among Postpartum Women
}

\author{
Amany Ahmed Gamal El-Dean Mahmoud*, Nada Ahmed Ismail ${ }^{* *}$, Maha Mohammed El- \\ Habashy*
}

ABSTRACT: In order to assess the dietary knowledge and practices among postpartum women we studied 420 recently delivered (within 2 months) women and reported to the specified centers for vaccination of their newborns were interviewed. An exploratory descriptive research design was adopted. The study was conducted at seven Maternal-child health centers in Alexandria, EGYPT. An interview schedule was designed and utilized to collect the necessary data. It included sociodemographic characteristics, women's reproductive history, women's dietary practices, and women's knowledge about postnatal nutrition. Results yielded that the total nutrition knowledge scores of the subjects was poor. Where only $6.0 \%$ had good score. As regards the practice; most of the studied women $(90.2 \%)$ had added fenugreek and of them $79.2 \%$ had added moghat to their postnatal diet. While around half of they had omitted water intake. It can be concluded that there is poor level of knowledge regarding during postpartum period about well balanced diet.

\section{INTRODUCTION}

Maternal mortality and morbidity levels are key indicators of the public health situation in a country (WHO) 2000.(1) The Safe Motherhood Initiative (SMI) was launched 15 years ago with the aim of reducing high maternal mortality, particularly in poor countries, where maternal health care was identified as a priority. Despite this initiative, maternal mortality remains very high in low-income countries, and lack of access to maternal care facilities is a further contributing factor. Ninety-nine percent of maternal deaths occur in developing countries, most of them preventable, (2). To reduce maternal mortality, more investment in health systems is needed to improve the quality and coverage of delivery services and to provide prenatal and postnatal care for the poor. ${ }^{(1-3)}$

In both developed and developing countries, women and their newborn health during postpartum period have been

\footnotetext{
${ }^{* *}$ Obstetric and Gynecologic Nursing, Faculty of Nursing, University of Sana'a, Yemen

${ }^{*}$ Obstetric and Gynecologic Nursing, Faculty of Nursing, University of Alexandria
} 
neglected when compared with the attention that is given during pregnancy and childbirth. Such an eclipse ignores the fact that the majority of maternal deaths and disabilities occur during the postpartum period and that early neonatal mortality remains high. Poor quality care reduces the opportunities for health promotion, early detection and adequate management of problem and disease Therefore, quality post partum care is a long term investment in the future health of women and their newborn. ${ }^{(3)}$.

Postpartum period is a time of profound transition making great demands on the woman's resilience and capacity to adapt. So postpartum care includes the prevention, early detection and treatment of complications and diseases. Also, provision of advice and services regarding breastfeeding, birth spacing, immunization, and maternal nutrition. ${ }^{(4)}$. A good postpartum care in addition to a well balanced diet is very important for the health of a woman. The paramount importance of nutrition of a woman during pastpatum is widely recognized and has received increasing attention in recent years. In many Third World countries including Egypt, malnutrition is endemic, fertility rates are high, and women enter the reproductive stage at an early age and subsequently attain high parity and most of the time food based on cultural beliefs and practices in which food is one of the most universal symbols of culture, holding one of the key point in postpartum period..$^{(5-7)}$

Food habits and practices vary among people and are influenced by culture norms. Whether their foods supplies are limited or abundant, women tend to develop trends in eating that are derived from their sociocultural background. These will in turn influence their postpartum eating practices. ${ }^{(8-10)}$

Postpartum woman may have little or no nutritional knowledge. Nutritional counseling is often unavailable or ignored during 
postpartum period. Nurses working in maternal and child settings have a vital role in providing nutritional education to postpartum women; they are in a favored position to promote better nutrition and improvement of the health need of women. So they should seek every opportunity to help postpartum women select foods within their personal preferences that will promote their own well-being and successful lactation. It is important that nurses be able to identify women who are at risk for nutritional deficiencies and make sound dietary recommendations. The main role of the nurse in the nutritional education during postpartum period is nutritional counseling which should follow certain sequential steps that include assessment of nutritional needs, planning, teaching, and evaluation. $(11,12)$

Because of dangerous consequences of malnutrition in postpartum, the researchers felt the need to assess mother's knowledge and beliefs about dietary practices during postpartum. Such information will help in providing more specifically tailored nursing interventions to women during their postpartum period. This may lead to a more healthy nutritional practices during postpartum period and positively reflects on both women and newborns well-being

\section{MATERIAL AND METHODS}

\section{Material}

Design: The exploratory descriptive design was adopted

Settings:

This study was conducted at seven Maternal-Child health Centers $(\mathrm{MCH})$ in Alexandria. They were randomly selected, one from each of the following health Zones in Alexandria Governorate.

- El-Mandrarah health Center from El Montazh Zone.

- El-Gomrk MCH from El-Gomrk Zone.

- $\quad$ Moharm Bek MCH from Middle Zone.

- Smoha MCH from East Zone.

- $\quad$ El-Ameria MCH from El-Ameria Zone.

- Karmooz MCH from West Zone. 
- Borg El-Arab MCH from Borg El-Arab

Zone.

Subjects:

A convenient sample of $\mathbf{4 2 0}$ postpartum women attending the study settings for immunization of their newborns constituted the study sample. Sixty women were chosen from each of the above seven settings.

Tool of data collection:

An interview schedule was designed and utilized to collect the necessary data; it included four parts:Part one: includes sociodemographic characteristics of the study sample such as: age; level of education; occupation. Part two: contains questions to identify woman's reproductive history such as Gravidity and Parity, number of abortions. Part three: comprises women's dietary practices during postpartum such as: foods she omitted, adds, and why. Part four: includes Women's knowledge about postpartum nutrition such as: the importance of a well balanced diet during postpartum period; the sources and the importance of each food group during postpartum period.

A scoring system for women's knowledge regarding nutrition was adopted. The correct answers were predetermined according to the literature and the questions were coded accordingly. A score of one was given to each correct and complete answer, a score two was given to each correct but incomplete answer, and a score of tree was given to incorrect or doesn't know. The possible range of total scores was zero to 39 which as classified as follows: good knowledge (75\% or more correct answers); fair knowledge (50\% to less than $75 \%$ correct answers); and Poor knowledge (less than $50 \%$ correct answers).

\section{Methods}

An official permission was obtained from the executive directors of Health Affairs Department in Alexandria and health centers mentioned before to conduct the study and collect the necessary data. 
The study tool was developed by the researchers after extensive review of the relevant current literature. Then it was tested for content validity by 5 juries who are expert in the related field to reach consensus on the best form to be implemented.

For testing the tool's feasibility the Pilot study was carried out on 35 women. The data was collected through the interview technique; where each subject was individually interviewed.

After data were collected; they were coded and transformed into a specially designed format so as to be suitable for computer entry. All entered data were verified for errors. Data analysis was carried out by using (SPSS12) program. The collected data were categorized, coded, computerized, tabulated, and analyzed.

\section{RESSULET}

Table (1) shows that, more than half $(60.2 \%)$ of the study sample were in their late twenties or early thirties While slightly less than one-fourth $\mathbf{( 2 3 . 8 \% )}$ of them fell in the age group $(15-<25)$ years. Only $16 \%$ of them were 35 years old or more.

Nearly one half $(\mathbf{4 7 . 4 \% )}$ of the sample had a secondary education. Almost a quarter $(\mathbf{2 4 . 3} \%)$ of them had a university education. While $16.9 \%$ and $11.4 \%$ of them had either a primary/preparatory education or were illiterate, respectively.

Most of them (85.2\%) were housewives, and from urban residence (81.2\%). Interestingly enough, almost all of them $(99.5 \%)$ felt that their income is adequate. About three-quarters (75.2\%) had small families ( $\leq 4$ members), while the rest (24.8\%) had larger families (> 4 members).

Table (2) demonstrates that $62.1 \%$ of them were pregnant for two or three times, while $30.7 \%$ of them were primigravida and only $\mathbf{7 . 1 \%}$ had got pregnant four times or more. It is noticed that $\mathbf{6 2 . 1 \%}$ of them had given two or three births, while $\mathbf{3 3 . 8 \%}$ of them had one birth and the rest (4.1\%) had given births four times or more. In relation to 
abortions, only $\mathbf{1 4 . 5} \%$ had a history of one or more abortions.

As regards number of children, it is noticed that $62.6 \%$ of the study sample had two or three children, while $\mathbf{3 3 . 8 \%}$ had one child and few (4.1\%) had four or more.

As regards antenatal follow-up during last pregnancy, most of them (89.8\%) had adequate ante-natal visits (4 times or more). The majority of study sample (83.1\%) had no health problems during last pregnancy.

Almost all of the study sample (99.5\%) had normal labor and delivery, and an almost equal proportion of them (95.9\%) had normal current puerperium. While only $3.3 \%$ had anemia and $\mathbf{0 . 7} \%$ had bleeding.

Breast-feeding was the pattern of newborn's feeding among $\mathbf{9 0 . 5 \%}$ of them. Only $\mathbf{2 . 4 \%}$ were bottle-fed and $\mathbf{7 . 1} \%$ gave a mixed feeding

Table (3) exhibits that about one-third of the study sample $(\mathbf{3 0 . 7 \% )}$ gave correct and complete answer about the definition of a well balanced diet,
The majority of the study sample $(\mathbf{8 8 . 8 \% )}$ had revealed correct knowledge but not complete about the importance of a well balanced diet, only $4.8 \%$ of them had revealed correct and complete knowledge about the importance of well balanced diet.

It was observed that only $0.5 \%$ of the study sample gave correct and complete answer about the importance of protein, while about two-thirds (66.4\%) gave correct but incomplete answer and one-third (33.1\%) gave wrong answer or did not know. As regards the sources of protein, it was found that more than half of the study sample (55.2\%) gave correct but incomplete answer, while $\mathbf{2 2 . 4 \%}$ of them gave correct and complete answer and the same percentage (22.4\%) gave incorrect answer or did not know.

Regarding the importance of carbohydrate, the table revealed that only $0.5 \%$ of study sample gave correct and complete answer. However, $43.5 \%$ gave correct but incomplete answer and slightly, 
more than half $(56 \%)$ of study sample gave wrong answer or did not know. More than half of the study sample (69.5\%) gave correct but incomplete answer about the source of carbohydrate, and about one-sixth (14.3\%) gave correct and complete answer, and the rest (16.2\%) gave incorrect answer or did not know.

In relation to the types of vitamins, it was found that only $\mathbf{2 . 4 \%}$ of study sample gave correct and complete answer. However; similar percentages $(\mathbf{4 8 . 8 \% )}$ ) of them gave either a correct but incomplete answer or incorrect answer. Regarding the importance of vitamins, this table revealed that $59.3 \%$ of study sample gave correct but incomplete answers. While $\mathbf{4 0 . 7 \%}$ gave incorrect or did not know. As regards sources of vitamins, it was noticed that $3.3 \%$ of study sample gave correct and complete answer. While 58.1\% gave correct but incomplete answer and the rest (38.6\%) gave incorrect answer or did not know.

Table (4) shows, that the majority of study sample (79.8\%) gave correct but incomplete answer about importance of fluid, whereas less than one-fifth $(15.7 \%)$ of them gave the correct and complete answer, and only $4.5 \%$ gave wrong answer or did not know.

Regarding their knowledge about the amount of fluid requirements; about half of them $(39.5 \%)$ said that it is more than one liter per day, while almost one-third (33.1\%) of them reported one liter or less, and more than one-forth (27.4\%) did not know.

Table (5) indicates that a substantial proportion of study sample (71.9\%) had taken three meals per day, while about one quarter of them (24.5\%) had taken two meals, and $\mathbf{2 . 6 \%}$ had taken one meal per day. Regarding snacks, it was found that about half of study sample (53.8\%) had not taken any snacks, while about one-third of study sample (34.8\%) had taken once a day and only $11.4 \%$ of them have taken twice snakes per day.

According to Table (6) almost all (90.2\%) 
women in the study sample had added fenugreek to their dietary intake. As much as $79.2 \%$ had added Moghat, and only $\mathbf{8 . 3 \%}$ had added Halawa and just $1 \%$ of them had added dates.

Table (7) shows that the main reason for fenugreek consumption was (68.2\%) enhancing breast milk secretion, therefore, enhancing lactation. This was followed by promotion of lochial expulsion (46.8\%), i.e., cleansing uterine cavity. While only $13.1 \%$ had consumed it for prevention of after pains. Few of them had other reasons such as replacement of blood loss (7.2\%) or strengthen their bones (5.3\%) or replacement of water loss (13.1\%).

About three-quarters of Moghat consumers (75.3\%) believed that it strengthens their bones, thus improving their general health. Nearly one-third (38.1\%) of them believed it improves lactation. Other reasons were for promoting lochial expulsion (14.4\%), replacement of blood loss (11.7\%); and only $1.2 \%$ of them said it prevents after pains. Women in the study sample had added dates to their postpartum diet to strengthen their bones (50\%) and/or improve milk secretion for better lactation.

According to Table (8) ;around half (51.7\%) of the postpartum women omitted water, while $\mathbf{4 1 . 0 \%}$ of them omitted spicy foods, and slightly more than one-quarter (27.9\%) omitted cold fluids. About one-sixth (14.8\%) of them had omitted salty food and $3.6 \%$ had omitted green vegetable. The rest (1\%) had omitted soft drinks.

Table 9 states that' Slightly less than half $(\mathbf{4 8 . 3} \%)$ of the women who omitted water claimed that it causes abdominal enlargement, $\mathbf{3 4 . 1} \%$ said it causes maternal and/or newborn colic, $\mathbf{2 7 . 1 \%}$ stated it prevents lochial discharge, and only $\mathbf{5 . 9 \%}$ of them did not gave any reason. About one half $(\mathbf{4 7 . 7 \% )}$ of the women who had omitted spicy foods from their postpartum diet had attributed this for fear of maternal or newborn constipation, $\mathbf{3 0 . 8} \%$ claimed that it 
causes colic, $11 \%$ had believed that it harms the baby. Less than one-tenth (6.8\%) of them had believed that its consumption is wrong, though they did not know why. Cold fluids were also omitted, and almost three-fourths $\mathbf{( 7 5 . 2 \% )}$ of them did so for fear of colic, $\mathbf{3 5 . 8 \%}$ stated that it stops lochial discharge, and $10.2 \%$ said it causes abdominal expansion. The reasons for omitting salty foods were: abdominal colic (35.4\%), following traditions (29.1\%), constipation (19.3\%), baby protection (12.9\%), and enhancement of lochial expulsion (3.2\%). Green vegetables were omitted because they believed it causes colic $(\mathbf{7 3 . 3} \%)$, constipation $(\mathbf{1 3 . 3 \% )}$; or for non-specific reason (13.3\%). Indigestion $(\mathbf{1 0 0 \% )}$ was the only reason given for omission of sauce by all who did so. Soft drinks were omitted for two equal reasons: prevention of colic (50\%) and improvement of milk secretion (50\%).

Table (10) indicates that a few (1.4\%) of women in the study sample had followed a specific dietary regime for the whole postpartum period (40 days). About twothirds $(67.6 \%)$ of them did so for only one week. Nearly one-fourth (24.5\%) of them had extended it to two weeks. While only $6.4 \%$ of them had elongated to three weeks.

Table (11) demonstrates that the majority of study sample's knowledge (96.9\%) was coming from their family members. While about one quarter of study sample (24.8\%) had got their knowledge from media, $\mathbf{1 2 . 1 \%}$ got it from their friends or neighbors, and only $\mathbf{1 4 . 5 \%}$ of them got it from either an obstetrician or a nurse.

\section{DISCUSSION}

The postpartum period is one of the Special times in a women's life. It is a time for the woman to think about her lifestyle, habits, and diet and how they affect her and her child as well as consider if she wishes to adopt healthy habits that will be beneficial for both of them now and in the future. Therefore, good nutrition in the postpartum 
period is important for the health and reproductive performance of women and the health, survival, and development of their newborns. As a result, inadequate resources and efforts have been allocated for improving women's nutrition especially during postpartum period. The Committee on Recommended Dietary Allowance (RDA) of Food and Nutrition Board considers the optimum diet for postpartum woman to be one that supplies somewhat more of each nutrient than that recommended for nonpregnant female. ${ }^{(13-16)}$

The results of the current study revealed that most of the study subjects lacked the basic and essential knowledge regarding the importance of a well balanced diet during postpartum period, different food elements (protein, carbohydrate, fat, vitamins, minerals, and water), its importance and their sources. This is not in accordance with Doran's results who found, in a study done in Ontario-Canada, that although most of his study sample $(70 \%)$ were below the poverty line, yet they were well educated and knowledgeable about dietary requirements during the postpartum period. Therefore, their knowledge and skills had enabled them to eat postnatally as well as those with higher socioeconomic status. He further added that the dietary inadequacies among his sample were more likely due to lack of resources and not of nutritional knowledge. Where mothers often view their own nutritional needs as secondary and sacrifice their own diet in order to provide food for their children. ${ }^{(17)}$

This dissimilarity in the findings of the present study and those of Doran can be attributed to the fact that most of the current study sample was housewives and lacking adequate access to information about nutrition during postpartum period. It can be also attributed to lack of provision of enough information from the medical or nursing staff - in the study settings - about the healthy diet for woman during postpartum period. The postpartum women's diet should 
compose of approximately $60 \%$ of carbohydrate $(<10 \%$ of which is composed of refined sugars), $20 \%$ protein, and 20$25 \%$ fat $^{(14)}$ and for many Vitamins and minerals. In general, nutritional requirements during this period are higher than during pregnancy. Foods, rather than supplements, are the preference sources of these nutrients because foods provide a plethora of health. ${ }^{(18)}$

Women in the present study did not have enough knowledge about the importance of fluids and its needed amount during postpartum period. Postpartum mothers should be encouraged to drink $2 L$ to $3 L$ of fluids each day. Fluids intake must be adequate to maintain milk production. However, the guide to how much fluids that postpartum mother should drink is to "drink to thirst." There is no empirical evidence to show that forcing fluids will increase milk supply. Yet, drinking too much water (over 12 glasses a day) can actually decrease milk supply. ${ }^{(19 . .22)}$
The results of this study revealed that most women $(71.9 \%)$ did not change the number of meals per day (three meals per day) postnatal. However, the amount of food and its type had changed during the postpartum period especially during the first week after delivery. This result is in agreement with El-Khyat's results ${ }^{(22,23)}$ who found that the majority of postpartum women in Tanta did take three meals per day.

Changing the type of food during postpartum period was observed in the findings of this current study in which women added some special foods during this period such as Date ;and Halawa Tahinia, hot drink such as fenugreek and Moughat. They also added Dates and Halawa Tahina to their food postnatally. They did so in order to replace blood loss, improve lactation; and strengthen their bones. This result is in accordance with Osman's results who did a similar study in Sudan. The postpartum women in the 
present study believed that consumption of Halawa Tahinia helps in enhancing milk production and secretion for lactation. Halawa Tahini is popular in the western part of the Balkans, Middle East, and other areas surrounding the Mediterranean Sea. Osman, in Sudan had also found that Sudanese women consumed Halawa to improve breast feeding and to clean the uterus. ${ }^{(23.24)}$

The reasons given by the women for consumption of fenugreek was to improve milk secretion, promote lochai expulsion, prevent afterpains, and replace blood loss. They also drank this herb instead of water because they omitted water in the first week after delivery because they believed that water causes abdominal enlargement. This is in line with Thairu's results ${ }^{25}$, who reported that postnatal women in Tanzania consume fenugreek to promote lochial expulsion.

Fenugreek seeds have been used medicinally all through the ages and were held in high repute among the Egyptians, Greeks, and Romans for medicinal and culinary purposes. ${ }^{(26.27)}$ It appears to be the herb that is most often used to increase milk supply. Fenugreek seeds contain estrogen precursors that increase milk supply. However, scientists do not know for sure how this happens. Some believe it is possible because breasts are modified sweat glands, and fenugreek stimulates sweat production. Some researches found that fenugreek can increases a nursing mother's milk supply within 24 to 72 hours after first taking the herb. Consequently many women today take fenugreek in a pill form (ground seeds placed in capsules). Fenugreek can also be taken in tea form, although tea is believed to be less potent than the pills and the tea comes with a bitter taste that can be hard to stomach. ${ }^{(28-30)}$ It is an excellent galactagogue, and has been used as such for centuries. In one study of ten women, "the use of fenugreek significantly increased volume of breast 
milk(26). However fenugreek may be not right for everyone since the herb has caused aggravated asthma symptoms in some women and has lowered blood glucose levels in some other women with diabetes. ${ }^{(31)}$

The present study revealed that women omitted the intake of some foods/fluids during postpartum period as they believed that these foods are not good either for themselves or for the baby, further they may inhibit both milk secretion and lochial expulsion. The postpartum dietary and lifestyle habits vary greatly among different countries and cultures where most of these omissions are culturally imposed.(32) In western countries, instead of restrictions, women are encouraged to eat a wellbalanced diet from all food categories. ${ }^{(32)}$ In the present study, women had omitted water intake because they believed that water causes abdominal enlargement, colic; and prevents lochial expulsion. However, some women did so for no definite reason except following the traditions and obeying the advice of their family care givers (mother/mother in law). This omission is most commonly seen during the first week of postpartum period where they consume a lot of fenugreek instead of water. This is in accordance with these results. Thi et al., who reported that Vietnamese women believe in postpartum water intake limitation in order to tighten their abdominal content and prevent urine ailment when they grow old. ${ }^{(33)}$ The Vietnam's cultural beliefs in the lay theory of balance between 'am' and 'duong' or 'cold' and 'hot' (similar to yin and yang in Chinese culture). Where Women after delivery are considered as in imbalanced of 'am' and 'duong'. In the other words, postpartum women are in extremely imbalance toward yin. In this case, their bodies are in 'cold' stage because they lost blood and energy during child birth. As a result, hot foods and fluids intake are a cultural remedy to restore the balance. However, foods and fluids categorization as 
"cold" or "hot" does not refers to its temperature, but to other culturally determined measures ${ }^{(34)}$, where hot herbal tea is considered to be one of the cold fluids. Although women consume the hot water, the plain water is considered neutral and the herbal tea is considered 'cool' thing. Combining with the hot food prescription, the consumption of drink is believed to neutralize between the idea of hot food for cold status and cool drink for good breast milk. ${ }^{(34)}$

Women in the current study state that they omitted Spicy foods because they believed that it causes constipation, colic, and flatus either for themselves or the baby. They also believed that it may harm the baby through breast milk. Yet, some women did not give any reason for such omission as in case of omission of water where the practice was just a blind obedience to postpartum customs and traditions. This result is not in accordance with Kaewsarn et als., results who reported that $73.6 \%$ of Thi women believed that spicy foods positively affect baby's health and uterine involution. ${ }^{(34)}$ Obikeze also had found in a study on Cambodian postpartum women that their food should be very spicy so that the hotness from the food will heat up the body and strengthen their health. (35) This difference in the practices reflects a differences in cultural believes about food in general. These culture beliefs that childbirth leaves the mother cold and wet, so she needs to eat hot foods to balance the cold status that she had experienced through out childbirth.

Furthermore, in the present study the reasons for omission of salty foods (such as pickles) from postpartum diet are fear of abdominal colic, constipation, and baby harm. Yet, some women did not know why they did so. This disagrees with Obikeze 's results who reported that Cambodian postpartum women prefer salty foods as they believe that salt makes the women thirst so that she will consume more 
water. (35) This difference could be attributed to that Egyptian women especially primi, with episiotomy were afraid of rupture of sutures due to constipation so they tried to be away from any kinds of foods that may cause constipation and in turn affected the wound.

From the present study it revealed that two-thirds of the sample were sticking to a specific dietary regime during postpartum period that lasted for only the first seven postnatal days. This duration extended to forty days for mothers who had delivered for the first time than who have multi deliveries. This may be due to the family's concentration on the diet of the primigravida where she usually has no say about what to eat for forty days postnatal. This result is in line with those of Choudhr, (36) who found out that most Indian women did so for 40 days postnatal. However, Thi et al., ${ }^{(33)}$. Had found that Vietnamese women follow more or less the same pattern. However, the duration of postpartum dietary regime among them was much longer (25-100 days).

It is very interesting to notice that Vietnamese women stick to postnatal diet for as long as 100 days which is beyond 3 months. This observation may be attributed to the fact that most of the Thi et al., study sample were living within extended families that hold this tradition. ${ }^{(33)}$ While, in both Egypt and India it was observed that the duration of postpartum dietary regime was longer among primigravida than multipara. Again most of the primi women in these both studied areas had stayed under the care of their mothers or mothers inlaw for only the 40 days postnatal.

From the results, it is clear that the family's members play important roles on the postpartum health and nutritional knowledge and practices in comparison to medical professional. Health professionals need to be aware of women's cultural 
beliefs and practices and carefully consider the extension to which their care complemented these. ${ }^{(34)}$ Selected interventions and dietary advice can affect a woman's nutritional status during this period.(27) Health education influences one's nutrition and health care knowledge, behavior, and attitude toward postpartum practices. Thus, when promoting contemporary postpartum practices, health education courses should be encouraged. (32)

The reasons given by the mothers for adopting particular or special foods during postpartum period illustrated the magnitude of their nutritional ignorance. Where only a small fraction of them had stated that they were consuming a nutritious diet during this period such as protein rich foods. Others stated that their dietary practices were based on an inherited dietary customs such as the intake of Moghat. Whether the reasons for intake of such foods are rational or irrational, good dietary practices must be reinforced and the women must be encouraged to take nutritious foods during all postpartum period. Unhealthy dietary practices such as water omission should be corrected.

\section{CONCLUSIION}

\section{Based on the findings of the present} study, it can be concluded that:

- Traditional dietary postpartum practices are still dominant in contemporary Egyptian culture and perpetuated by close female relatives especially mother. These practices are embedded within the socio-cultural status.

- Poor level of knowledge regarding the general nutrition during postpartum period as balanced diet, different food elements, its sources and its importance during this period, importance of fluids; and the amount needed during postpartum period.

- The daily requirements of different food groups, milk and milk products, meat, 
poultry and eggs, vegetables, fruits, bread, cereals; rice, and pasta groups according to 24 hours did not meet the Dietary Requirement Allowance.

- Although the majority of the study sample omitted water during the first week of the postpartum period, they consumed other fluids such as fenugreek.

- The majority of the study sample stuck to a specific dietary regime during postpartum period that lasted for only the first seven postnatal days. This duration extended to forty days for mothers who had delivered for the first time.

- Family members mostly the mother, play an important role on the postpartum mother's health and decision regarding to dietary postpartum practices.

\section{RECOMMENDATIONS}

Based on the findings of the present study, the following recommendations are suggested:

- Nutritional education for postpartum mothers should be propagated by mass media with the widest possible coverage.

- Health care professionals should put a well-defined plan for the health care of the postpartum woman that includes screening for nutritional problems and providing dietary guidance.

In-service training programs about nutrition should be conducted for all health care providers, nutritional educators, and counselors including maternity nurses.

Nutritional assessment and counseling during postpartum period should be an integral part of the postnatal care, especially in the primary care. 
Table (1): Distribution of the study sample according to their socio-demographic characteristics

\begin{tabular}{|c|c|c|}
\hline \multirow{2}{*}{ Characteristics } & \multicolumn{2}{|c|}{$\mathrm{N}=420$} \\
\hline & No. & $\%$ \\
\hline \multicolumn{3}{|l|}{ Age in year } \\
\hline$-15-$ & 100 & 23.8 \\
\hline$-25-$ & 253 & 60.2 \\
\hline$-\geq 35$ & 67 & 16.0 \\
\hline \multicolumn{3}{|l|}{ Education } \\
\hline - illiterate & 48 & 11.4 \\
\hline - primary or preparatory school & 71 & 16.9 \\
\hline - secondary school & 199 & 47.4 \\
\hline - high education & 102 & 24.3 \\
\hline \multicolumn{3}{|l|}{ Occupation } \\
\hline - house wife & 358 & 85.2 \\
\hline - employee & 52 & 12.4 \\
\hline - Worker & 10 & 2.4 \\
\hline \multicolumn{3}{|l|}{ Residence } \\
\hline - urban & 341 & 81.2 \\
\hline - Rural & 79 & 18.8 \\
\hline \multicolumn{3}{|l|}{ Income } \\
\hline - enough & 418 & 99.5 \\
\hline - More than enough & 2 & .5 \\
\hline \multicolumn{3}{|l|}{ No. of family member } \\
\hline-4 or less & 316 & 75.2 \\
\hline - More than 4 & 104 & 24.8 \\
\hline
\end{tabular}


Table (2): Distribution of the study sample according to their Obstetric characteristics

\begin{tabular}{|c|c|c|}
\hline \multirow{2}{*}{ Obstetrical characteristics } & \multicolumn{2}{|c|}{ No. $=420$} \\
\hline & No. & $\%$ \\
\hline $\begin{array}{l}\text { Gravidity } \\
\text { - one } \\
-2 \text { or } 3 \\
-4 \text { or more }\end{array}$ & $\begin{array}{c}129 \\
261 \\
30\end{array}$ & $\begin{array}{c}30.7 \\
62.1 \\
7.1\end{array}$ \\
\hline $\begin{array}{l}\text { Parity } \\
\quad \text { - one } \\
-2 \text { or } 3 \\
-4 \text { or more }\end{array}$ & $\begin{array}{c}142 \\
261 \\
17\end{array}$ & $\begin{array}{c}33.8 \\
62.1 \\
4.1\end{array}$ \\
\hline $\begin{array}{l}\text { No. of Abortion } \\
\text { - not at all } \\
\text { - one or more }\end{array}$ & $\begin{array}{c}359 \\
61 \\
\end{array}$ & $\begin{array}{l}85.5 \\
14.5 \\
\end{array}$ \\
\hline $\begin{array}{l}\text { No. of a live children } \\
\text { - one } \\
\text { - } 2 \text { or } 3 \\
\text { - } 4 \text { or more }\end{array}$ & $\begin{array}{c}140 \\
263 \\
17\end{array}$ & $\begin{array}{c}33.3 \\
62.6 \\
4.0\end{array}$ \\
\hline $\begin{array}{l}\text { Number of ante-natal visits during last pregnancy } \\
\text { - less than } 4 \text { times } \\
\text { - more than } 4 \text { times }\end{array}$ & $\begin{array}{c}43 \\
377\end{array}$ & $\begin{array}{l}10.2 \\
89.8\end{array}$ \\
\hline $\begin{array}{l}\text { Health problems during last pregnancy } \\
\text { - nothing } \\
\text { - anemia } \\
\text { - hypertension } \\
\text { - hypotension }\end{array}$ & $\begin{array}{c}349 \\
12 \\
25 \\
34\end{array}$ & $\begin{array}{c}83.1 \\
2.9 \\
6.0 \\
8\end{array}$ \\
\hline $\begin{array}{l}\text { Health problems during last delivery } \\
\text { - nothing } \\
\text { - bleeding }\end{array}$ & $\begin{array}{c}418 \\
2 \\
\end{array}$ & $\begin{array}{c}99.5 \\
.5 \\
\end{array}$ \\
\hline $\begin{array}{l}\text { Health problems during current postpartum } \\
\text { - nothing } \\
\text { - bleeding } \\
\text { - anemia }\end{array}$ & $\begin{array}{c}403 \\
3 \\
14\end{array}$ & $\begin{array}{c}95.9 \\
.7 \\
3.3\end{array}$ \\
\hline
\end{tabular}


Table (3): Distribution of the study sample according to their knowledge about nutrition during postpartum

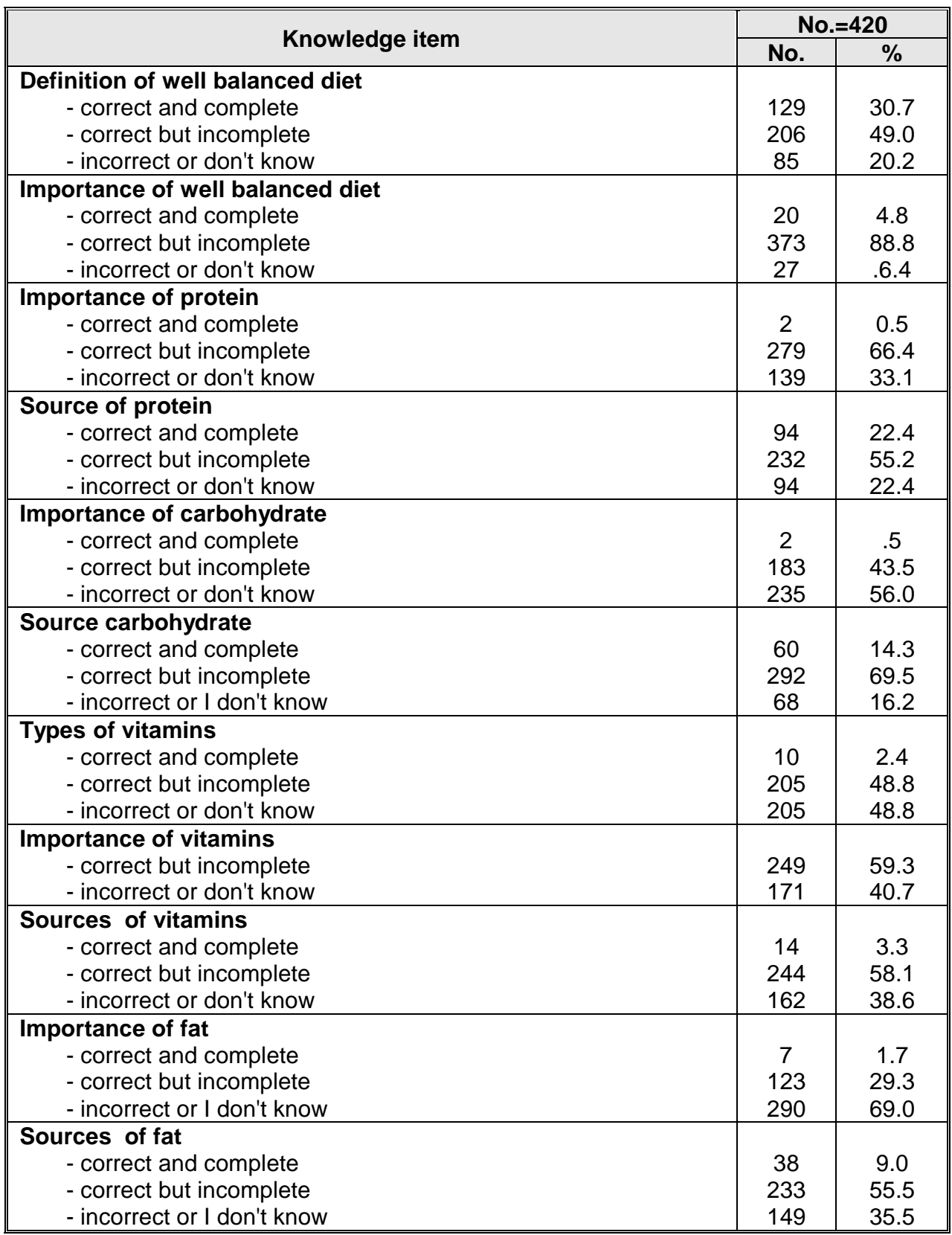


Table (4): Distribution of the study sample according to their Knowledge about fluids during postpartum period.

\begin{tabular}{|c|c|c|}
\hline \multirow{2}{*}{ Knowledge item } & \multicolumn{2}{|c|}{ No. $=420$} \\
\hline & No. & $\%$ \\
\hline $\begin{array}{l}\text { Importance of fluid } \\
\text { - Correct and complete } \\
\text { - Correct but incomplete } \\
\text { - Incorrect or don't know }\end{array}$ & $\begin{array}{c}66 \\
335 \\
19\end{array}$ & $\begin{array}{c}15.7 \\
79.8 \\
4.5\end{array}$ \\
\hline $\begin{array}{l}\text { Amount of daily fluid requirement } \\
\text { - More than one litter } \\
\text { - One litter or less } \\
\text { - Doesn't know }\end{array}$ & $\begin{array}{l}166 \\
139 \\
115\end{array}$ & $\begin{array}{l}39.5 \\
33.1 \\
27.4\end{array}$ \\
\hline
\end{tabular}

Table (5): Distribution of the study sample according to the number of daily meals and snacks consumed daily during postpartum period

\begin{tabular}{||l|c|c|}
\hline \multicolumn{1}{|c|}{$\begin{array}{c}\text { Number of meals and } \\
\text { snakes/day during } \\
\text { postpartum }\end{array}$} & No. & $\%$ \\
\cline { 2 - 3 } & & \\
\hline Meals & 11 & 2.6 \\
- one meal & 103 & 24.5 \\
- two meals & 302 & 71.9 \\
- three meals & 4 & 1.0 \\
- four meals or more & 226 & 53.8 \\
\hline Snacks & 146 & 34.8 \\
- nothing & 48 & 11.4 \\
- once & & \\
- Twice & \multicolumn{2}{|c||}{} \\
\hline
\end{tabular}

Table (6) Distribution of study sample according to the type of foods/fluids that were added during postpartum period

\begin{tabular}{||l|c|c||}
\hline \multicolumn{1}{|c|}{ Type of added foods/fluids } & \multicolumn{2}{c|}{$\mathbf{N = 4 2 0}$} \\
\cline { 2 - 3 } & No. & $\%$ \\
\hline - Fenugreek & 374 & 90.2 \\
- Moghat & 333 & 79.2 \\
- Halawa Tahinia & 35 & 8.3 \\
- Dates & 4 & 1 \\
\hline
\end{tabular}


Table(7): Distribution of study sample according to their reasons for adding certain foods/fluids during postpartum period

\begin{tabular}{|c|c|c|c|c|c|c|c|c|c|c|c|c|}
\hline \multirow{3}{*}{$\begin{array}{l}\text { Added } \\
\text { foods/fluids } \\
\text { items }\end{array}$} & \multicolumn{12}{|c|}{ Reasons } \\
\hline & \multicolumn{2}{|c|}{$\begin{array}{c}\text { Strengthen } \\
\text { mother's } \\
\text { bone }^{*}\end{array}$} & \multicolumn{2}{|c|}{$\begin{array}{l}\text { Improves } \\
\text { lactation* }\end{array}$} & \multicolumn{2}{|c|}{$\begin{array}{c}\text { Promotes } \\
\text { lochial } \\
\text { expulsion* }\end{array}$} & \multicolumn{2}{|c|}{$\begin{array}{l}\text { Replaces } \\
\text { blood loss* }\end{array}$} & \multicolumn{2}{|c|}{$\begin{array}{l}\text { Prevents } \\
\text { afterpain }\end{array}$} & \multicolumn{2}{|c|}{$\begin{array}{c}\text { Replaces } \\
\text { water* }^{*}\end{array}$} \\
\hline & No. & $\%$ & No. & $\%$ & No. & $\%$ & N0. & $\%$ & No. & $\%$ & N0. & $\%$ \\
\hline $\begin{array}{l}\text { Fenugreek } \\
\text { No. } 374\end{array}$ & 20 & 5.3 & 255 & 68.2 & 175 & 46.8 & 27 & 7.2 & 49 & 13.1 & 13 & 13.1 \\
\hline $\begin{array}{l}\text { Moghat } \\
\text { No. } 333\end{array}$ & 251 & 75.3 & 127 & 38.1 & 48 & 14.4 & 39 & 11.7 & 4 & 1.2 & 0 & 0 \\
\hline $\begin{array}{l}\text { Date } \\
\text { No. } 4\end{array}$ & 2 & 50 & 2 & 50 & 0 & 0 & 4 & 100 & 0 & 0 & 0 & 0 \\
\hline $\begin{array}{l}\text { Halawa Tahina } \\
\text { No. } 35\end{array}$ & 0 & 0 & 35 & 100 & 0 & 0 & 0 & 0 & 0 & 0 & 0 & 0 \\
\hline
\end{tabular}

*Total is not exclusive, i.e., each subject gave more than one answer

Table (8) Distribution of study sample according to the type of foods/fluids which were omitted during postpartum period

\begin{tabular}{|c|c|c|}
\hline \multirow{2}{*}{ Type of omitted foods/fluids } & \multicolumn{2}{|c|}{$\mathrm{N}=420$} \\
\hline & No. & $\%$ \\
\hline - water* & 217 & 51.7 \\
\hline - spicy food* & 172 & 41.0 \\
\hline - cold fluid* & 117 & 27.9 \\
\hline - salty food* & 62 & 14.8 \\
\hline - green vegetable* & 15 & 3.6 \\
\hline - soft drink* & 4 & 1.0 \\
\hline
\end{tabular}




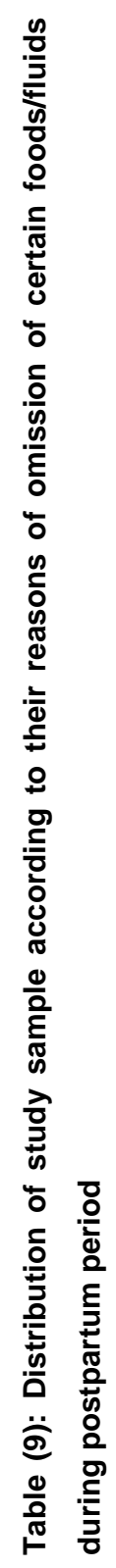

\begin{tabular}{|c|c|c|c|c|c|c|c|c|}
\hline & \multirow{2}{*}{ 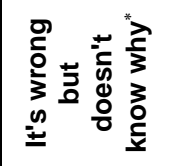 } & $\circ$ & م) & $\underset{0}{\infty}$ & 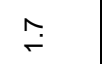 & $\bar{S}$ & $\stackrel{m}{\stackrel{m}{p}}$ & 0 \\
\hline & & $\dot{\mathbf{z}}$ & $\stackrel{m}{\stackrel{m}{2}}$ & $\simeq$ & $\sim$ & $\stackrel{\infty}{\sim}$ & $\sim$ & 0 \\
\hline \multirow{2}{*}{\multicolumn{2}{|c|}{ Indigestion }} & $\circ$ & 0 & 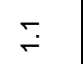 & 0 & $\stackrel{\sim}{\infty}$ & $\circ$ & $\circ$ \\
\hline & & $\dot{\dot{z}}$ & 0 & $\sim$ & 0 & $\sim$ & 0 & 0 \\
\hline & \multirow{2}{*}{ 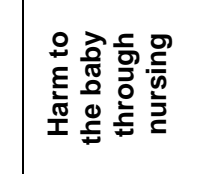 } & $\circ$ & 0 & $\mp$ & 0 & $\stackrel{\stackrel{\sim}{\mathfrak{I}}}{\sim}$ & 0 & 0 \\
\hline & & $\dot{\dot{z}}$ & 0 & $\stackrel{\rho}{\Gamma}$ & 0 & $\infty$ & 0 & 0 \\
\hline \multirow{4}{*}{ 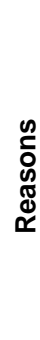 } & \multirow{2}{*}{ 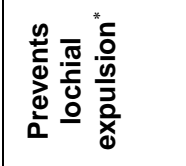 } & $\circ^{\circ}$ & $\bar{N}$ & 0 & $\begin{array}{l}\infty \\
\stackrel{\infty}{\rho} \\
\stackrel{\rho}{n}\end{array}$ & $\underset{\text { ల్ }}{\tilde{N}}$ & 0 & 0 \\
\hline & & $\dot{0}$ & 吕 & 0 & ₹ & $\sim$ & o & 0 \\
\hline & \multirow{2}{*}{ 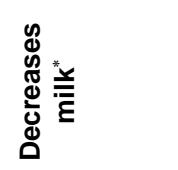 } & $\circ$ & 0 & ○ & 0 & 0 & 0 & in \\
\hline & & $\dot{0}$ & $\circ$ & 0 & 0 & 0 & $\circ$ & $\sim$ \\
\hline \multirow{2}{*}{\multicolumn{2}{|c|}{ 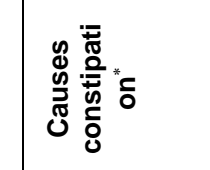 }} & $\circ^{\circ}$ & o. & $\stackrel{\hat{\sigma}}{\hat{\sigma}}$ & $\stackrel{\cong}{=}$ & $\stackrel{m}{\stackrel{m}{+}}$ & $\stackrel{m}{\stackrel{m}{m}}$ & $\circ$ \\
\hline & & $\dot{\dot{q}}$ & $\sim$ & ఋ & $\sim$ & $\stackrel{\simeq}{\simeq}$ & $\sim$ & 0 \\
\hline \multirow{2}{*}{\multicolumn{2}{|c|}{ 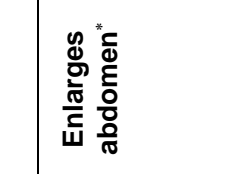 }} & $\circ$ & 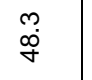 & $\stackrel{\infty}{i}$ & $\stackrel{\sim}{\circ}$ & 0 & $\circ$ & $\circ$ \\
\hline & & $\dot{\dot{z}}$ & $\stackrel{\leftrightarrow}{\circ}$ & ナ & $\simeq$ & 0 & ○ & $\circ$ \\
\hline \multirow{2}{*}{\multicolumn{2}{|c|}{ 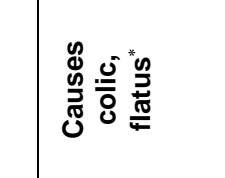 }} & $\circ$ & $\overline{\dot{m}}$ & 㐫 & $\underset{\substack{n \\
\text { L }}}{n}$ & $\stackrel{\vec{m}}{\dot{m}}$ & $\stackrel{m}{i}$ & in \\
\hline & & $\stackrel{\dot{\theta}}{\mathbf{z}}$ & $\stackrel{N}{N}$ & ณొ & $\infty_{\infty}^{\infty}$ & $\approx$ & $\mp$ & $\sim$ \\
\hline \multicolumn{2}{|r|}{ 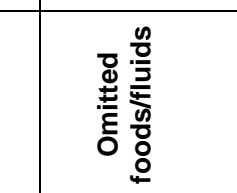 } & & 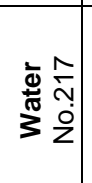 & 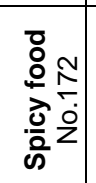 & 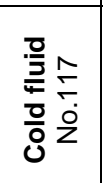 & 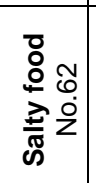 & 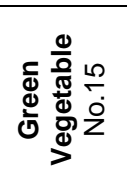 & 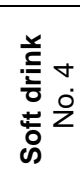 \\
\hline
\end{tabular}


Table (10) Distribution of the study sample according to the duration of sticking to a specific dietary regime during the postpartum period

\begin{tabular}{||l|c|c||}
\hline \multicolumn{1}{|c|}{ Duration in days } & \multicolumn{2}{c|}{ No.=420 } \\
\hline - Seven & No. & $\%$ \\
- Fourteen & 284 & 67.6 \\
- Twenty-one & 103 & 24.5 \\
- Forty & 27 & 6.4 \\
\hline
\end{tabular}

Table (11): Distribution of the study sample according to the sources of knowledge about nutrition during postpartum period

\begin{tabular}{|l|c|c|}
\hline \multicolumn{1}{|c|}{$\begin{array}{c}\text { Source of postpartum nutritional } \\
\text { knowledge }\end{array}$} & No. & $\%$ \\
\hline & & \\
\hline & 407 & 96.9 \\
- Family & 104 & 24.8 \\
- Media & 61 & 14.5 \\
- Medical professiona* & 51 & 12.1 \\
- Friends/neighborhood & & \\
\hline
\end{tabular}

*Total is not exclusive, i.e., each subject gave more than one answer 


\section{REFERENCES}

1. World Health Organization. World Health DaySafe Motherhood. Geneva: WHO; 1998

2. United Nations. 2000 a better world for all. Geneva: UN; 2000

3. Salhan S. Process Documentation of the Initiative to "Improve the Quality of Maternal Health through Implementation of Facility-Based Review of Maternal Deaths". Regional Health Forum. 2005; 9 (1):19-20

4. World Health Organization. Postpartum Care of the Mother and Newborn: A practical guide. Geneva: WHO;1998

5. World Health Organization. Reduction of maternal mortality: Action for safe motherhood. A joint WHO/UNFPA/UNICEF/World Bank statement. Geneva: WHO; 1999.

6. Decherney A, Nathan L. Current Obstetric and Gynecologic Diagnosis and Treatment. 9th ed. New York: McGraw-Hill; 2003. 245-246.

7. Didona $\mathrm{N}$, Marks $\mathrm{M}$, Kumm $\mathrm{R}$. Introductory Maternal-Newborn Nursing. Philadelphia: Lippincott Willims \& Wilkins; 1996. 238

8. Maimbolwa M, Yamba B. Cultural Childbirth Practices and Beliefs in Zambia. Journal of Advanced Nursing. 2003; 43 (3): 263-74

9. Mattson S. Working Toward Cultural Competence Working. A WHONN Lifelines. 2000; 4 (4): 41-3

10. World Health Organization. Maternal Mortality in 2000. Geneva: WHO; 2004

11. Davis J, Sherer K. Applied Nutrition and Diet Therapy for Nurse. $2^{\text {nd }}$ ed. Philadelphia: W.B. Saunders; 1994. 411

12. Patty R. Wilson C, Pugh L. Promoting Nutrition in Breastfeeding Women.
American Society for Clinical Nutrition. 2005; 34(1):120-4

13. Jose O, Penelope S. Improving Prenatal Nutrition in Developing Countries: Strategies, Prospects, and Challenges. American Society for Clinical Nutrition. .2000;71(3):1353-63

14. American Dietetic Association. Nutrition and Women's Health. Available from: http://www.adajournal.org 2005

15. World health organization. Considerations for Formulating Reproductive Health Laws. Geneva: WHO; 2000

16. World Health Organization. Healthy Eating during Pregnancy and Breastfeeding: Booklet for mothers. Geneva: WHO; 2001

17. Doran L. Energy and Nutrient Inadequacies in the Diets of LowIncome Women who Breast-feed. Journal of the American Dietetic Association. 1997;(97)1:1283-7

18. Dudek S. Nutrition Essentials for Nursing Practice. 5th ed. New York: Lippincott Williams\&Willkins; 2006. 297-299

19. Pillitteri A. Maternal and Child Health Nursing. 4thed. Philadelphia: Lippincott Williams \&Wilkins; 2003.598

20. Levitt C, Shaw E, Wong S, Kaczorowski J, Springate R, Sellors J, et al. Systematic Review of the Literature on Postpartum Care: Methodology and Literature Search Results. BIRTH. 2004; 31(3): 169-202.

21. Klossner N, Hatfield N. Introductory Maternity and Pediatric Nursing. Philadelphia: Lippincott Willims \& Wilkins; 2006; 289- 298. 
22. National Academy of Sciences, Institute of Medicine. Nutrition during Lactation. National Academy of Sciences Committee on Nutritional Status; Subcommittee on Lactation report. Washington, DC: National Academy Press;1991

23. El-Khyat E. Study to Assess the Dietary Patterns of Puerperal Women in Tanta. M.S. Thesis. Alexandria University, Faculty of Nursing. 1986:84-92.

24. Osman A. Dietary Practices and Aversion during Pregnancy and Lactation among Sudanese Women. Journal of Tropical Pediatrics. 1985;31(2):16-9

25. Thairu L. Maternal Diet during Postpartum Seclusion: an Ethnographic Study among the Swahili Pemba, Tanzania. African Journal of Food, Agriculture, nutrition and Redevelopment. 2004; (4)1

26. Tiran D. The Use of Fenugreek for Breast feeding Women. Complementary therapies in Nurse Midwifery. Churchill Livingstone; 2003; 9: 155-156

27. Westfall RE. Galactagogue Herbs: A Qualitative Study and Review. Canadian Journal of Midwifery Research and Practice. 2003; 2(2):227.

28. Dimri U. Fenugreek. Available fom:http://www.breastfeeding.com/ 2006

29. Curtis S. Fenugreek and Breastfeeding. Avia;ab;e from: http://www.breastfeedingonline.com.2004
30. Swafford S, Berens B. Effect of Fenugreek on Breast Milk Production. ABM News and Views. 2000; 6 (3):1625

31. Tiran D. The Use of Fenugreek for Breast Feeding Women. Complementary Therapies in Nursing \& Midwifery. 2003; 9:155-56

32. Liu N, Mao L, Sun X, Liu L, Chen B, Ding Q. Postpartum Practices of Puerperal Women and Their Influencing Factors in Three Regions of Hubei, China. BMC Public Health. 2006, 6:274

33. Thi L, Pasandarntorn W, Rauyajin $O$. Traditional Postpartum Practices among Vietnamese Mothers in Anthi district, Hung Yen Province. Journal of the American Dietic Association. 2003;10(30): 599-607

34. Kaewsarn P, Moyle W, Creedy D. Traditional Postpartum Practices among Thai women. Journal of Advanced Nursing. 2003; 41(4): 35866

35. Obikeze A. Indigenous Postpartum Maternal and Child Health Care Practices among the Igbo of Nigeria. Health and Population. Midwifery. 1997; 5:177-8

36. Choudhry U. Traditional Practices of Women From India: Pregnancy, Childbirth, and Newborn Care. 1997;JOGNN 26: 533-539

37. World Health Organization. Postpartum Care of the Mother and Newborn. Geneva: WHO; 1998. 